\title{
Malvidin Protects WI-38 Human Fibroblast Cells Against Stress-induced Premature Senescence
}

\author{
Hye Rin Seo ${ }^{1}$, Mi Jin $\mathrm{Choi}^{1}$, Ji Myung Choi ${ }^{2}$, Jong Cheol Ko${ }^{2}$, Jee Yeon $\mathrm{Ko}^{2}$, Eun Ju Cho ${ }^{1}$ \\ ${ }^{1}$ Department of Food Science and Nutrition, Pusan National University, Busan, ${ }^{2}$ Department of Southern Area Crop Science, National Institute \\ of Crop Science, Rural Development Administration, Miryang, Korea
}

\begin{abstract}
Background: Malvidin is one of the most abundant components in red wines and black rice. The effects of malvidin on aging and lifespan under oxidative stress have not been fully understood. This study focused on the anti-aging effect of malvidin on stress-induced premature senescence (SIPS) in WI-38 human lung-derived diploid fibroblasts.

Methods: In order to determine the viability of WI-38 cells, MTT assay was conducted, and malondialdehyde level was determined using thiobarbituric acid-reactive substance assay. Protein expression of inflammation-related factors was also evaluated by Western blot analysis. Results: Acute and chronic oxidative stress via hydrogen peroxide $\left(\mathrm{H}_{2} \mathrm{O}_{2}\right)$ treatment led to SIPS in WI-38 cells, which showed decreased cell viability, increased lipid peroxidation, and a shortened lifespan in comparison with non- $\mathrm{H}_{2} \mathrm{O}_{2}$-treated WI-38 cells. However, malvidin treatment significantly attenuated $\mathrm{H}_{2} \mathrm{O}_{2}$-induced oxidative stress by inhibiting lipid peroxidation and increasing cell viability. Furthermore, the lifespan of WI-38 cells was prolonged by malvidin treatment. In addition, malvidin downregulated the expression of oxidative stress-related proteins, including NF-kB, COX-2, and inducible nitric oxide synthase. Furthermore, protein expression levels of p53, p21, and Bax were also regulated by malvidin treatment in WI-38 cells undergoing SIPS.
\end{abstract}

Conclusions: Malvidin may potentially inhibit the aging process by controlling oxidative stress.

(J Cancer Prev 2016;21:32-40)

Key Words: Aging, Senescence, Malvidin, Oxidative stress, Fibroblasts

\section{INTRODUCTION}

Reactive oxygen species (ROS), including singlet oxygen, superoxide anions, hydroxyl radicals, and hydrogen peroxide, are a general output of aerobic metabolism and can also originate in response to insults such as heat, cytokines, hydrogen peroxide, and radiation. ${ }^{1,2}$ Under normal conditions, antioxidants in the body control ROS content; however, inadequate antioxidant content or ROS overproduction can result in pathophysiological conditions. The aging process is closely related to increased ROS levels. Excessive ROS accumulation disturbs normal biological redox balance and pushes organisms toward an oxidized condition that induces oxidative stress. ${ }^{3.5}$ Impaired homeostasis owing to ROS accumulation induces cellular damage and aging-related degenerative diseases. In addition, oxidative stress can trigger specific signaling pathways that can alter gene expression via activation of particular transcription factors. Oxidative stress can trigger the expression of inflammation-related factors such as NF- $\mathrm{KB}$ and its downstream genes, including inducible nitric oxide synthase (iNOS) and COX-2, eventually leading to aging through persistent inflammatory responses. ${ }^{2,6,7}$ This upregulation of inflammatory reactions is common in age-related diseases such as cancer. Aging and environmental factors result in oxidative stress, and it causes metabolic changes including elevation of lipid peroxidation, ROS, protein, and DNA oxidation. Furthermore, DNA damage induced by reactive species may cause aberrant cell cycle entry and affect gene regulation of p53 and Wnt related with neurodegenerative diseases and cancer.

Received January 19, 2016, Revised February 15, 2016, Accepted February 15, 2016

Correspondence to: Eun Ju Cho

Department of Food Science and Nutrition, Pusan National University, 2 Busandaehak-ro 63beon-gil, Geumjeong-gu, Busan 46241, Korea

Tel: +82-51-510-2837, Fax: +82-51-583-3648, E-mail: ejcho@pusan.ac.kr, ORCID: Eun Ju Cho, http://orcid.org/0000-0003-4282-3219

Copyright (c) 2016 Korean Society of Cancer Prevention

(c) This is an Open Access article distributed under the terms of the Creative Commons Attribution Non-Commercial License (http://creativecommons.org/licenses/by-nc/4.0) which permits unrestricted non-commercial use, distribution, and reproduction in any medium, provided the original work is properly cited. 
Upregulation of p53 and downregulation of Wnt are associated with apoptosis of neural cells, whereas the downregulation of p53 and upregulation of Wnt induce proliferation of cancer cells. Therefore, inflammation and oxidative stress caused by aging are considered as a general initiating factor of both neurodegeneration and carcinogenesis. ${ }^{8}$ In addition, oxidative stress regulates apoptosis-associated transcription factor, such as Bax and Bcl-2., ${ }^{9} 10$ Aging, various age-related diseases, and even cell death can occur due to the effects of oxidative stress on cell signaling and gene expression. ${ }^{2}$

Antioxidants are capable of attenuating ROS-induced damage associated with oxidative stress by scavenging free radicals, including hydroxyl radicals and superoxide anions, thus protecting organisms against the aging process. Malvidin (molecular weight: 331.3), one of the most abundant components of red wines and black rice, is an anthocyanidin that is well known for antioxidant. Previous studies revealed its anti-oxidative and anti-inflammatory effects in RAW 264.7 macrophages and antihypertensive effect through inhibiting angiotensin I-converting enzyme. ${ }^{6,11}$ In addition, malvidin inhibited TNF- $\alpha$-induced increase of inflammatory factors, including monocyte chemoattractant protein-1 and intercellular adhesion molecule 1 , and hindered the production of vascular cell adhesion molecule 1 in the NF- $\kappa B$ pathway in endothelial cells. ${ }^{12}$ However, the effects of malvidin on aging and lifespan under oxidative stress have not been reported.

Human diploid fibroblasts (HDFs) are a well-established experimental model for cellular aging-related studies. In cell culture, HDFs divide a limited number of times and cease growing and this phenomenon is known as cellular replicative senescence (RS). Following exposure to sub-lethal stressors such as ROS, HDFs show a cellular stress-induced premature senescence (SIPS) phenotype that is similar to the general morphology of cellular $\mathrm{RS}^{2,13}$ This study investigated whether the anti-aging effect of malvidin and its associated mechanisms could protect WI-38 human fibroblast cells in SIPS against aging. In addition, the effect of malvidin on lifespan was examined.

\section{MATERIALS AND METHODS}

\section{Materials and reagents}

Malvidin was purchased from Extrasynthese Co. (Genay, France). Basal medium eagle (BME), Triton X-100, and paraformaldehyde were obtained from Sigma-Aldrich Chemical Co. (St. Louis, MO, USA). $\mathrm{H}_{2} \mathrm{O}_{2}$, calcium and magnesium-free PBS, MTT, dimethyl sulfoxide (DMSO), dimethyl formaldehyde, potassium ferrocyanide, Nonidet P-40 (NP-40), potassium ferricyanide, 2-amino-2-hydroxymethyl-1,3-propanediol (Tris), and phenylmethane sulfonyl fluoride (PMSF) were purchased from Wako Pure Chemical Industries Ltd. (Osaka, Japan). FBS and trypsin solution were obtained from Life Technologies Inc. (Grand Island, NY, USA), and 5-bromo-4-chloro-3-indoyl-b-D-galactoside was obtained from Nakalai (Kyoto, Japan). Anti-iNOS, anti-COX-2, and anti- $\beta$-actin were obtained from Santa Cruz Biotechnology (Santa Cruz, CA, USA), and goat anti-rabbit IgG horseradish peroxidaseconjugated secondary antibodies were obtained from Amershan Corp. (Arlington Heights, IL, USA).

\section{Cell culture and treatment}

WI-38 cells (human normal embryonic lung-derived diploid fibroblasts, population doubling level [PDL] 23) were purchased from the ATCC (American Type Culture Collection, Manassas, VA, USA) and grown in BME with 10\% FBS in an incubator with a $5 \%$ $\mathrm{CO}_{2}$ atmosphere. Cultured cells were re-fed 2-3 times per week, washed with PBS, and separated with 0.05\% trypsin-0.02\% EDTA. The collected cells were added to medium and subcultured at an interval of 4-5 days. Upon reaching confluence, WI-38 HDFs at PDL 26.0 were seeded at a density of $1 \times 10^{5}$ cells $/ \mathrm{mL}$ in 6 - or 96-well culture plates and incubated for 2 hours. To induce acute and chronic oxidative stress, the method of Wolf et al. ${ }^{14}$ was used with slight modification. In case of acute oxidative stress, cells were treated with $50 \mu \mathrm{M} \mathrm{H}_{2} \mathrm{O}_{2}$ for 1 hour, followed by treatment with malvidin for 24 hours. In addition, chronic oxidative stress was induced by treating $5 \mu \mathrm{M} \mathrm{H}_{2} \mathrm{O}_{2}$ repeatedly for 4 days, with the malvidin treatment process also repeated for 4 days.

\section{Cell viability}

Cell viability was evaluated using the MTT colorimetric assay devised by Mosmann. ${ }^{15}$ MTT solution $(1 \mathrm{mg} / \mathrm{mL}$ ) was added to each well of a 96-well culture plate, which was incubated for 4 hours at $37^{\circ} \mathrm{C}$. After removing the medium containing MTT, DMSO was added to solubilize formazan crystals incorporated into viable cells. The absorbance of each well was read at $540 \mathrm{~nm}$ using a Microplate Reader (Model 3550-UV; Bio-Rad, Tokyo, Japan).

\section{Thiobarbituric acid-reactive substance levels}

Thiobarbituric acid (TBA)-reactive substance levels were evaluated using the method of Mihara and Uchiyama. ${ }^{16}$ Cell lysates were treated with $0.67 \%$ TBA and $20 \%$ trichloroacetic acid and boiled at $100^{\circ} \mathrm{C}$ for 45 minutes. The resulting mixtures were cooled on ice and extracted with $\mathrm{n}-\mathrm{BuOH}$. Centrifugation was 
conducted at 4,000 $\times$ gfor 10 minutes and the fluorescence of the $\mathrm{n}$-BuOH layer was measured at an excitation wavelength of 515 $\mathrm{nm}$ and an emission wavelength of $553 \mathrm{~nm}$ using a fluorescence spectrophotometer (model RF-5300PC; Shimadzu, Kyoto, Japan). Lipid peroxide content was calculated in terms of the amount of malondialdehyde (MDA).

\section{Cell lifespan}

Classification of life span in fibroblast (young and old age) was referred to previous studies, and their intermediate value was used for middle age. ${ }^{14,17}$ Cell lifespan was evaluated as described by Cristofalo and Charpentier. ${ }^{18}$ The PDL of each culture was calculated as follows: current PDL $=$ last PDL $+\log _{2}$ (collected cell number/seeded cell number).

\section{Protein extraction, gel electrophoresis, and western blot analysis}

Total cell lysates were obtained via lysis in an extraction buffer containing $25 \mathrm{mM}$ Tris- $\mathrm{Cl}$ (pH 7.5), $250 \mathrm{mM} \mathrm{NaCl}, 5 \mathrm{mM}$ EDTA, $1 \%$ NP-40, $0.1 \mathrm{mM}$ sodium orthovanadate, $2 \mu \mathrm{g} / \mathrm{mL}$ leupeptin, and $100 \mu \mathrm{g} / \mathrm{mL}$ PMSE. Nuclear proteins were extracted by the method of Komatsu et al. ${ }^{19}$ with slight modification for determining the activated NF-KB in nucleus level. Cells were lysed with lysis buffer containing $50 \mathrm{mM}$ Tris- $\mathrm{HCl}$ (pH 7.5), $10 \mathrm{mM} \mathrm{MgCl}_{2}, 15 \mathrm{mM} \mathrm{CaCl}_{2}$, $1.5 \mathrm{M}$ sucrose, $1 \mathrm{mM}$ dithiothreitol (DTT), and a protease inhibitor cocktail and placed on ice for 10 minutes. After centrifugation, nuclear pellets were resuspended in nuclear extraction buffer containing $20 \mathrm{mM}$ HEPES (pH 7.9), $15 \mathrm{mM} \mathrm{MgCl}_{2}, 0.42 \mathrm{M} \mathrm{NaCl}, 0.2$ mM EDTA, 25\% (v/v) glycerol, $10 \mathrm{mM}$ DTT, and a protease inhibitor cocktail. Centrifugation was conducted, after which nuclear proteins were concentrated in the supernatants. Protein concentrations were determined with a Bio-Rad protein assay kit (Bio-Rad, Hercules, CA, USA). For Western blot analysis, total proteins and nuclear proteins were separated by SDS PAGE and electro-transferred to nitrocellulose membranes (Schleicher \& Schuell, Keene, NH, USA), which were subjected to immunoblot analysis with the desired antibodies. Proteins on the membranes were visualized by enhanced chemiluminescence (ECL) (Amersham Corp.).

\section{Statistical analysis}

All analyses were performed using SAS software (SAS Institute Inc., Cary, NC, USA). Data are presented as mean $\pm \mathrm{SD}$. A value of $P<0.05$ was considered statistically significant. Differences between groups were evaluated by one-way ANOVA followed by Duncan's multiple range test.

\section{RESULTS}

1. Effects of malvidin on cell viability and thiobarbituric acid-reactive substance generation under hydrogen peroxide-induced premature senescence in WI-38 cells

The effects of malvidin treatment on cell viability and lipid peroxidation following $\mathrm{H}_{2} \mathrm{O}_{2}$-induced premature senescence in WI-38 cells are shown in Figure 1. The SIPS group treated with 50 $\mu \mathrm{M} \mathrm{H}_{2} \mathrm{O}_{2}$ showed $45 \%$ cell viability; however, the cell viability was improved by malvidin in a concentration-dependent manner. At a concentration of $0.5 \mu \mathrm{g} / \mathrm{mL}$, malvidin increased the cell viability to greater than $70 \%$ (Fig. 1A). The untreated group showed 0.45 $\mathrm{nmol} / \mathrm{mg}$ protein MDA, but the SIPS group showed $1.15 \mathrm{nmol} / \mathrm{mg}$ protein MDA (2.2-fold higher than that of the normal group). However, malvidin treatment at concentrations of $0.5,2.5$, and 10 $\mu \mathrm{g} / \mathrm{mL}$ decreased the MDA content to $0.53,0.47$, and 0.43 $\mathrm{nmol} / \mathrm{mg}$ protein, respectively (Fig. 1B).

In addition, repeated low-dose $\mathrm{H}_{2} \mathrm{O}_{2}$ treatment reduced WI-38 cell viability to $65 \%$ by inducing premature senescence through chronic oxidative stress (Fig. 1). However, malvidin treatment protected against SIPS induced by chronic oxidative stress and increased the cell viability in a concentration-dependent manner. At concentrations of 0.5 and $10 \mathrm{mg} / \mathrm{mL}$, malvidin increased the cell viability to $72 \%$ and $88 \%$, respectively (Fig. 1C). MDA level of the normal group was $0.13 \mathrm{nmol} / \mathrm{mg}$ protein, but that of the SIPS group under chronic oxidative stress was $0.49 \mathrm{nmol} / \mathrm{mg}$ protein. However, the MDA content in SIPS group was decreased significantly by repeated malvidin treatment. In particular, treatment with $10 \mu \mathrm{g} / \mathrm{mL}$ malvidin decreased the MDA content from 0.490 $\mathrm{nmol} / \mathrm{mg}$ protein to $0.15 \mathrm{nmol} / \mathrm{mg}$ protein (Fig. 1D).

\section{Effect of malvidin on the lifespan of WI-38 fibroblasts}

The effect of malvidin on WI-38 cell lifespan is shown in Table 1. In all age groups, malvidin treatment extended cellular lifespan. WI-38 cells at PDL 26 showed growth to PDL 64, while their lifespan was extended to PDL 67 by malvidin treatment. In the cells of moderate and extended age, malvidin treatment prolonged cellular lifespan in comparison with that of the non-treated group. Table 1 also shows the effects of malvidin on the lifespan of cells with SIPS induced by $\mathrm{H}_{2} \mathrm{O}_{2}$. In the young group, cell lifespan under SIPS induced by $\mathrm{H}_{2} \mathrm{O}_{2}$ showed a PDL of 28 . However, malvidin treatment recovered the cellular lifespan to PDL 34. In addition, malvidin treatment also extended the lifespan of the moderately aged group with SIPS to PDL 49, whereas the $\mathrm{H}_{2} \mathrm{O}_{2}$-treated moderately aged 
A

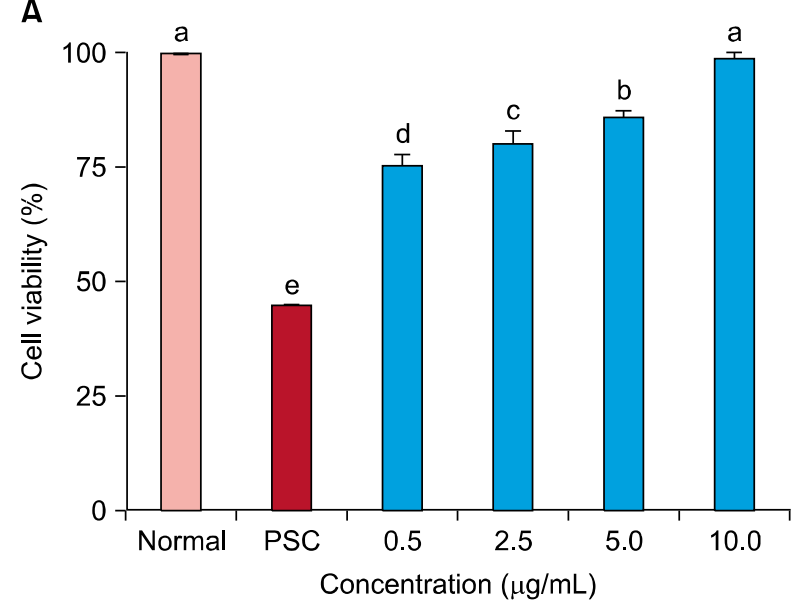

C

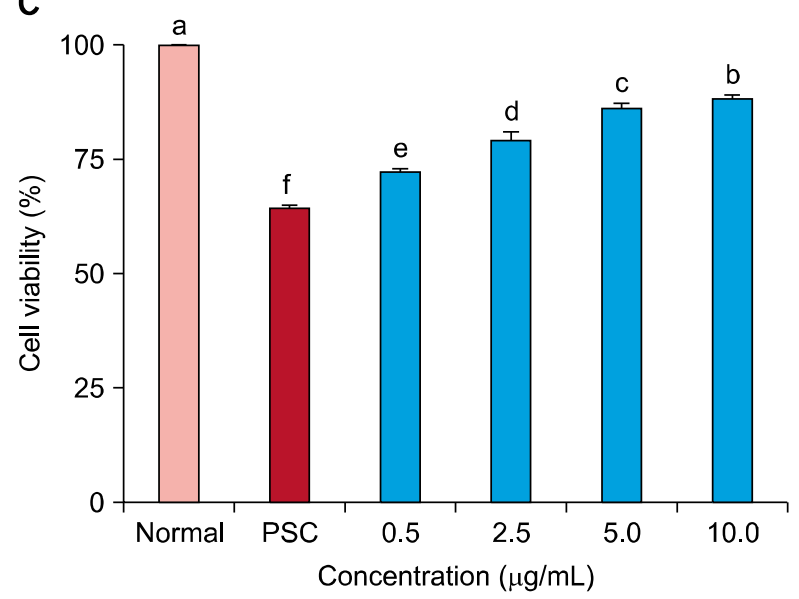

B

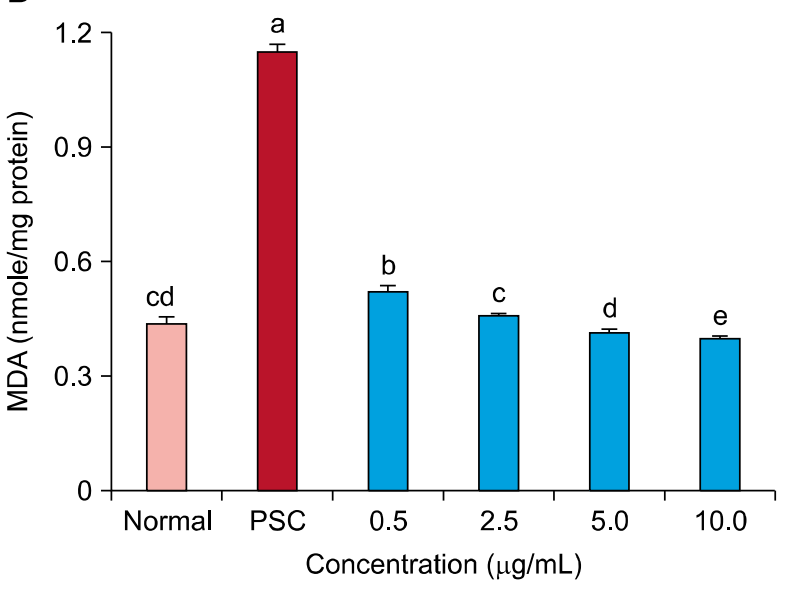

D

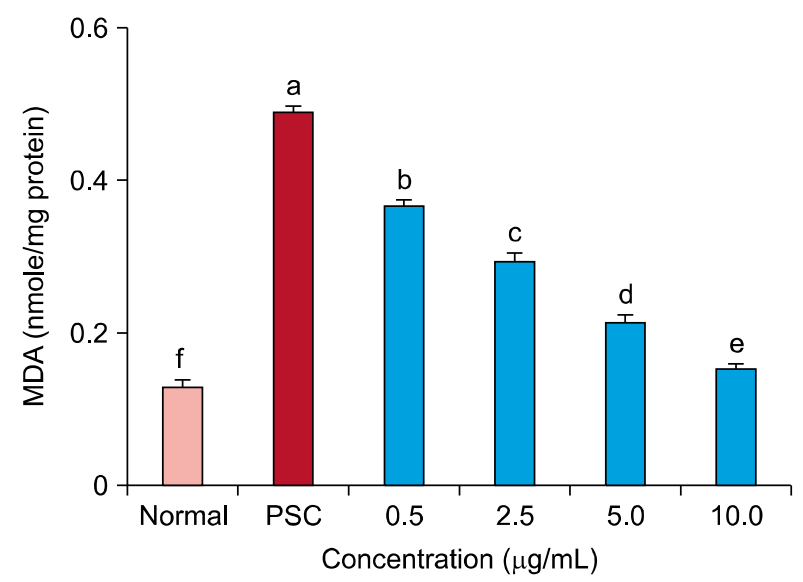

Figure 1. Effect of malvidin on cell viability and oxidative stress in WI-38 cells. (A) Cell viability and (B) thiobarbituric acid-reactive substance (TBARS) generation were measured after $\mathrm{H}_{2} \mathrm{O}_{2}$-induced premature senescence in WI-38 cells and (C) cell viability and (D) TBARS generation were also measured in WI-38 cells with premature senescence induced by repeated low-dose $\mathrm{H}_{2} \mathrm{O}_{2}$ treatment. Values are mean \pm SD (n $=6$ ). PSC, premature senescence control; MDA, malondialdehyde. ${ }^{a \mathrm{f}}$ Means with the different letters are significantly different $(P<0.05)$ by Duncan's multiple range test.

Table 1. Effect of malvidin on the lifespan of WI-38 fibroblast cells

\begin{tabular}{lcccc}
\hline & \multicolumn{5}{c}{ Life span (PDL) } \\
\cline { 2 - 5 } \multicolumn{1}{c}{ Group } & None & $\begin{array}{c}\text { Plus } \\
\text { malvidin }\end{array}$ & $\mathrm{H}_{2} \mathrm{O}_{2}$ & $\begin{array}{c}\mathrm{H}_{2} \mathrm{O}_{2} \text { plus } \\
\text { malvidin }\end{array}$ \\
\hline Young age (yr) & $26 \rightarrow 64$ & $26 \rightarrow 67$ & $26 \rightarrow 28$ & $26 \rightarrow 34$ \\
Middle age (yr) & $42 \rightarrow 62$ & $42 \rightarrow 66$ & $42 \rightarrow 42$ & $42 \rightarrow 49$ \\
Old age (yr) & $58 \rightarrow 62$ & $58 \rightarrow 63$ & - & - \\
\hline
\end{tabular}

$\mathrm{PDL}=$ last PDL $+\log _{2}$ (collected cell number/seeded cell number). PDL, population doubling level.

group of WI-38 cells showed a PDL of 42.

\section{Protective mechanisms of malvidin on stress- induced premature senescence}

Figure 2 shows the effect of malvidin on protein expression related to SIPS. Protein levels of NF- $\mathrm{KB}, \mathrm{COX}-2$, and iNOS were upregulated in the SIPS group in comparison with those of the normal group; however, malvidin treatment downregulated

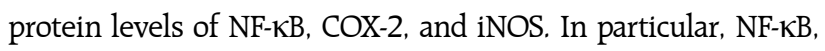
COX-2, and iNOS levels were markedly downregulated at a malvidin concentration of $10 \mu \mathrm{g} / \mathrm{mL}$. Exposure of WI-38 cells to $\mathrm{H}_{2} \mathrm{O}_{2}$ increased protein levels of p53 and p21; however, these protein levels were downregulated by malvidin treatment (Fig. 3). Figure 4 shows the protein levels of pro-apoptosis regulator Bax and anti-apoptosis regulator Bcl-2. Similar to other proteins related to oxidative stress, Bax protein expression was decreased by malvidin treatment in comparison with that of the SIPS group. In contrast, Bcl-2 expression was slightly increased by malvidin treatment (Fig. 4). 
A

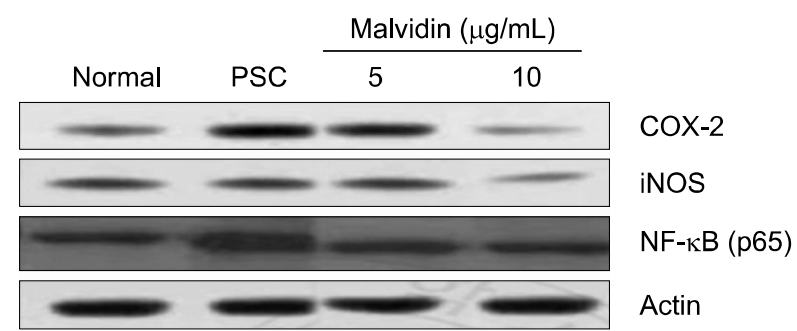

B

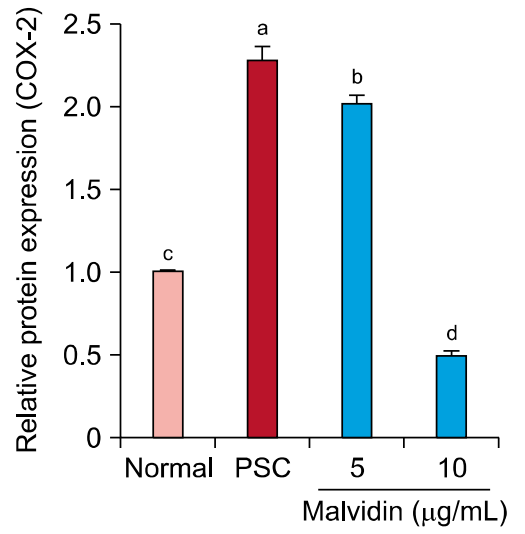

C

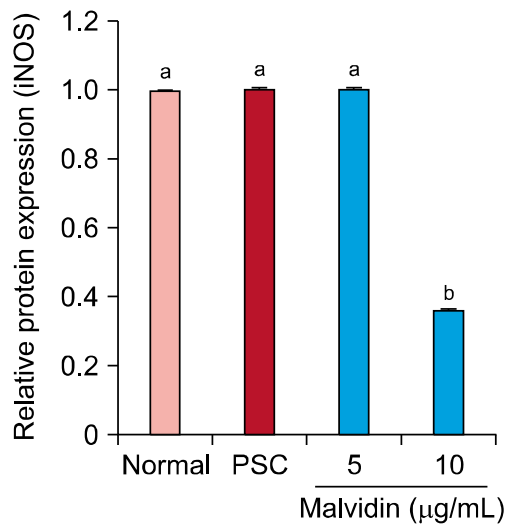

D

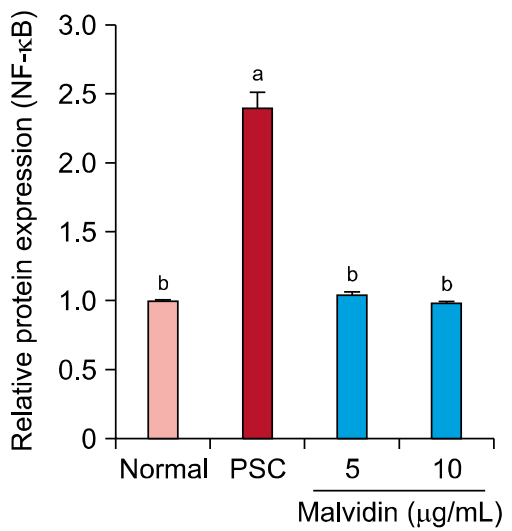

Figure 2. Effect of malvidin on protein expression of inducible nitric oxide (iNOS), COX-2, and NF- $\mathrm{KB}$ in WI-38 cells under $\mathrm{H}_{2} \mathrm{O}_{2}$-induced premature senescence. Cells were incubated with malvidin for 48 hours and lysed. Cellular and nuclear proteins were separated by SDS PAGE and transferred onto nitrocellulose membranes, which were probed with anti-NF- $\mathrm{KB}$, anti-COX-2, and anti-iNOS antibodies. (A) Proteins were visualized using an enhanced chemiluminescence detection system. Actin was used as an internal control. Graphs represent relative expression of (B) COX-2, (C) iNOS, and (D) nuclear NF-KB to actin expression. PSC, premature senescence control. ${ }^{\text {a d }}$ Means with the different letters are significantly different $(P<0.05)$ by Duncan's multiple range test.

A

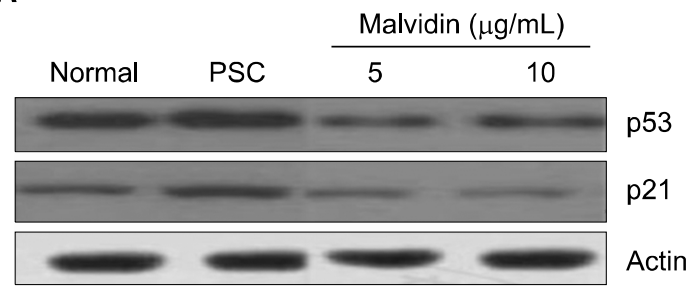

B

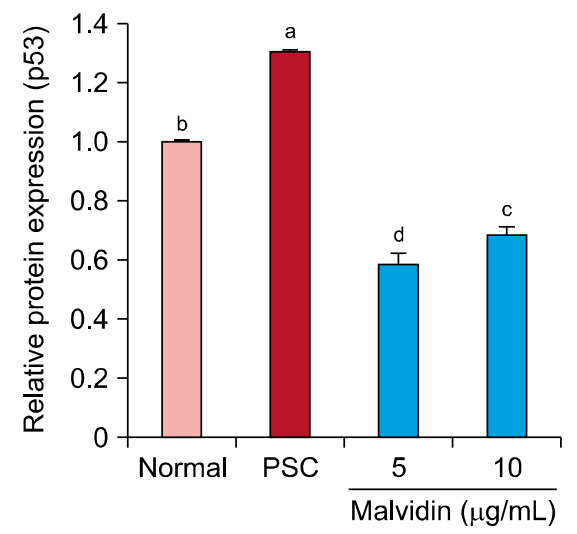

C

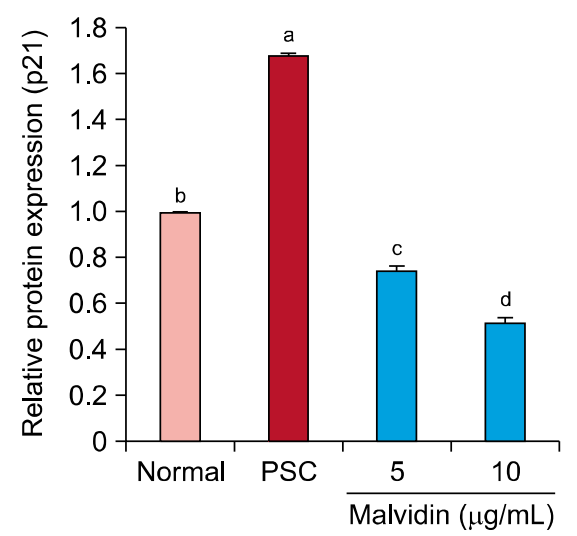

Figure 3. Effect of malvidin on protein expression of p53 and p21 in WI-38 cells under $\mathrm{H}_{2} \mathrm{O}_{2}$-induced premature senescence. Cells were incubated with malvidin for 48 hours. (A) The protein levels of p53 and p21 were detected by Western blotting. Actin was used as an internal control. Graphs represent relative expression of (B) p53 and (C) p21 to actin expression. PSC, premature senescence control. ${ }^{\mathrm{a} \sim \mathrm{d}}$ Means with the different letters are significantly different $(P<0.05)$ by Duncan's multiple range test. 
A

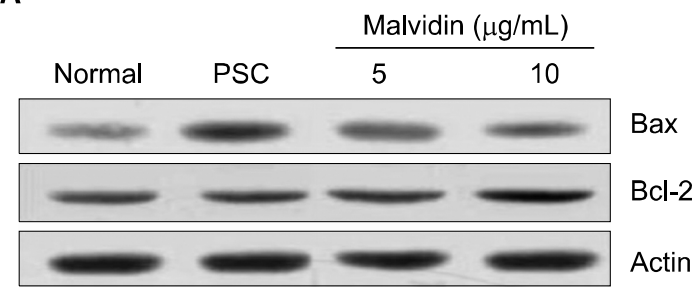

B

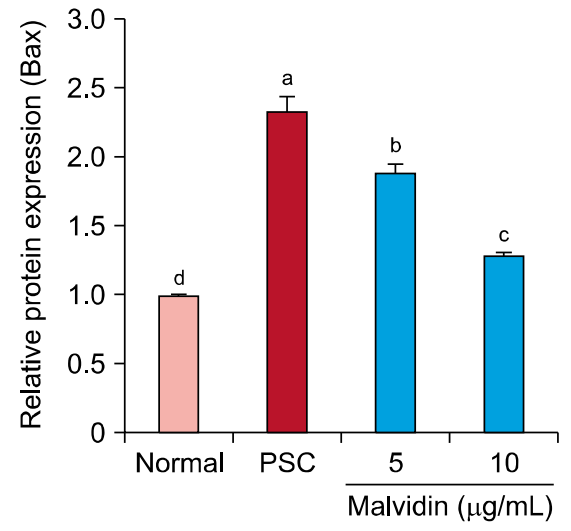

C

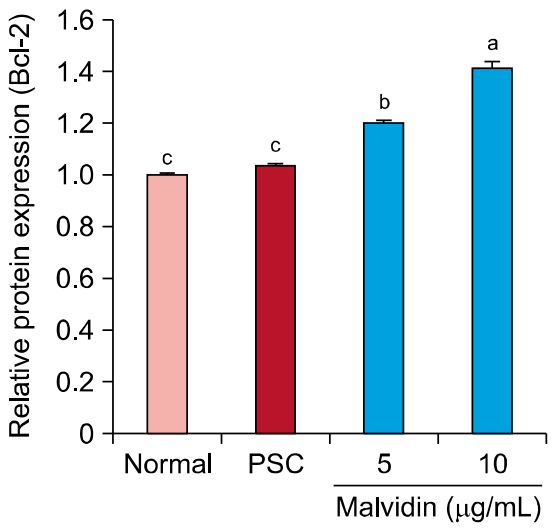

Figure 4. Effect of malvidin on protein expression of $\mathrm{Bax}$ and $\mathrm{Bcl}-2$ in WI-38 cells under $\mathrm{H}_{2} \mathrm{O}_{2}$-induced premature senescence. Cells were incubated with malvidin for 48 hours. (A) The protein levels of Bax and Bcl-2 were analyzed by Western blotting. Actin was used as an internal control. Graphs represent relative expression of (B) Bax and (C) Bcl-2 to actin expression. PSC, premature senescence control. ${ }^{\mathrm{a} \sim \mathrm{d}} \mathrm{Mea}-$ ns with the different letters are significantly different $(P<0.05)$ by Duncan's multiple range test.

\section{DISCUSSION}

ROS-induced oxidative stress is the factor primarily responsible for the aging process at both cellular and organism levels. ROS accumulation and oxidative stress increase with age and are accompanied by a decline in capability of the cellular recovery system. ${ }^{4}$ Therefore, aging is a progressive functional loss of the ability of an organism to withstand stress or insults. Aging is related to the occurrence of age-related diseases and death. ${ }^{20} \mathrm{In}$ addition, ROS production by the mitochondrial respiratory system can generate nitric oxide and reactive nitrogen species (RNS) during cellular metabolism, which affect cellular signaling pathways involving NF-KB, iNOS, p53, and COX-2, resulting in apoptosis or aging. ${ }^{21}$ Acute oxidative stress suppresses mitochondrial respiration and can lead to changes in membrane potential and abnormal morphology, which can also be caused by age-associated chronic oxidative stress during aging in a similar manner. ${ }^{22}$ Because oxidative stress is regulated by the balance between ROS levels and antioxidants in organisms and cellular system and anti- oxidants, studies on antioxidants have attracted much attention. Malvidin is an anthocyanin that has two $\mathrm{OCH}_{3}$ substituents on ring $B$, and previous study showed that malvidin is the strongest oxidation inhibitor in human low-density lipoproteins and lecithin liposome system among 5-different anthocyanins. ${ }^{23}$ Furthermore, it was demonstrated that malvidin and malvidin compounds including mavldin-3-glucoside, malvi- din-3-galctoside, and malvidin-3,5-digulcoside had anti-radical and anti-oxidative activity. ${ }^{24}$ The $\mathrm{O}_{2}$-scavenging activity of malvidin was higher than peonidin in a hypoxanthine-xanthine oxidase system. ${ }^{25}$ In addition, malvidin-3-glucoside was effective to attenuate intracellular reactive species generated by dihydrofluorescein diacetate, which has ability to permeate cell membranes and can be oxidized by reactive species. ${ }^{26}$ However, its protective effect against cellular senescence by oxidative stress using WI-38 cells has not been studied yet.

HDFs are a classical experimental model of cellular aging and age-related changes in human cells. ${ }^{27} \mathrm{HDFs}$ cease division after a definite number of population doublings in vitro in a process of limited cell division known as RS. ${ }^{13.28}$ Telomere shortening is observed at each cell division, leading to a telomere of certain length. ${ }^{28}$ SIPS in HDFs is a telomere-independent senescent phenotype model that can be induced by several factors, including exhaustion of cellular proliferation potential, alteration of electron transport potential, weakness of the antioxidant defense system, and oxidant generation. ${ }^{4}$ In addition, senescent HDFs display an increased cellular ROS level. Indeed, acute and chronic oxidative stress may induce a senescence phenotype in cells. ${ }^{29}$ Therefore, $\mathrm{H}_{2} \mathrm{O}_{2}$-induced SIPS in WI-38 HDFs is an appropriate model for the study of cellular aging and for assessing the anti-aging properties of agents effective against oxidative stress. Therefore, WI-38 cells were employed to assess the anti-aging effects of malvidin and to identify protective mechanisms that 
may explain its anti-aging activity in cells under SIPS.

Several studies have demonstrated delayed HDF growth under cellular senescence conditions. ${ }^{30,31}$ Consistent with these reports, our study demonstrated that SIPS was induced by acute and chronic oxidative stress, as manifested by decreased cell viability and increased lipid peroxidation. However, malvidin improved the viability of WI-38 cells under SIPS through attenuation of the oxidative stress induced by acute and chronic $\mathrm{H}_{2} \mathrm{O}_{2}$ treatment.

It is well established that oxidative stress exerts a negative influence on intracellular molecules including lipids, proteins, and DNA, and can even induce cellular senescence. ROS and RNS trigger excessive lipid peroxidation that is responsible for production of some biomarkers, such as MDA and 4-hydroxylnonenal. ${ }^{21,32}$ Human skin fibroblasts treated with ultraviolet-A, tert-butylhydroperoxide, and $\mathrm{H}_{2} \mathrm{O}_{2}$ showed increased levels of TBAreactive substances, indicating elevated cellular lipid peroxidation. ${ }^{33}$ In the current study, $\mathrm{H}_{2} \mathrm{O}_{2}$ exposure significantly elevated MDA content in WI-38 cells under SIPS (Fig. 1). However, malvidin treatment inhibited MDA production, suggesting that malvidin protects against oxidative stress.

Oxidative stress and inflammation play crucial roles in determining lifespan and mediate age-related disease. ${ }^{34}$ The lifespan of HDFs was extended by malvidin treatment (Table 1). Malvidin treatment effectively prolonged the lifespan of fibroblasts of all age groups. Moreover, malvidin treatment also increased the lifespan of HDFs with premature senescence induced by $\mathrm{H}_{2} \mathrm{O}_{2}$. It was established that there is a positive correlation between the cellular lifespan of an organism and its longevity. Fibroblasts show a reduced proliferative lifespan with age. In addition, fibroblasts of patients with syndromes of premature aging have a reduced lifespan. ${ }^{35,36}$ Therefore the current result demonstrating extension of the lifespan of HDFs by malvidin treatment indicates that malvidin may affect the lifespan of cells in vitro and the longevity of treated organisms, although further studies must be conducted to explore this possibility. These findings also suggest that malvidin could inhibit the aging process and increase lifespan.

$\mathrm{NF}-\mathrm{KB}$ is a ubiquitous transcription factor that is regulated by the intracellular reduction-oxidation state. A previous study has demonstrated the connection between NF- $\mathrm{KB}$ activation and aging. ${ }^{37}$ In its inactive state, NF- $\mathrm{BB}$ is attached to an inhibitory protein known as inhibitor of kappa B (IKB) in the cytoplasm. $\mathrm{NF}-\kappa \mathrm{B}$ is activated by separation from IKB, which is induced by various stimuli, including inflammation, infection, and oxidative stress. Oxidative stress induced by ROS, including $\mathrm{H}_{2} \mathrm{O}_{2}$ and external insults, can induce IKB phosphorylation, upon which it is degraded and separated from NF- $\mathrm{KB}$, which rapidly translocates from the cytoplasm to the nucleus and alters transcriptional activity. Because ROS, including $\mathrm{H}_{2} \mathrm{O}_{2}$, activate NF- $\mathrm{\kappa B}$ signaling, this pathway can be blocked by antioxidants such as vitamin $\mathrm{E}$ and butylated hydroxyanisole. ${ }^{37,38}$ NF- $\mathrm{KB}$ activation can cause both oxidative stress and inflammation. ${ }^{34}$ In addition, oxidative stress and the resulting lipid peroxidation may produce free radical chain reactions, activating $\mathrm{NF}-\mathrm{KB}$ signaling and accelerating the production of inflammatory mediators. ${ }^{34}$ Indeed, chronic oxidative stress as well as inflammatory reactions is positively associated with several disorders related to aging, while NF- $\kappa B$ activation increases with age due to inhibition of I $\kappa \mathrm{B} \alpha{ }^{39}$ It was demonstrated that malvidin attenuated nuclear translocation and DNA binding activity of NF- $\mathrm{BB}$ in both lipopolysaccharide (LPS)-treated and unstimulated RAW264.7 cells. In addition, investigation of LPS-induced NF- $\kappa B$ activation by luciferase reporter assay showed strong effect of malvidin in RAW264.7 cells. ${ }^{6}$ Consistent with these reports, our results revealed that SIPS triggered by $\mathrm{H}_{2} \mathrm{O}_{2}$ in WI-38 HDFs caused upregulation of $\mathrm{NF}-\mathrm{\kappa B}$. However, malvidin treatment downregulated NF- $\kappa B$ protein expression, demonstrating the inhibitory effect of malvidin on NF- $\mathrm{KB}$ signaling.

We also investigated protein expression of iNOS and COX-2. iNOS and COX-2 expression levels are regulated by translocation of activated NF- $\mathrm{KB}$ and mediate the aging process through tissue damage and chronic inflammation. ${ }^{40}$ iNOS is a crucial enzyme that produces $\mathrm{NO}$ and thus plays a major role in oxidative stress and inflammation. ${ }^{21}$ COX-2 also has a critical role in inflammation since it produces various prostaglandins associated with the pathogenesis of chronic diseases. ${ }^{21,41}$ Therefore, iNOS and COX-2 are considered to be useful biomarkers of cellular oxidation. ${ }^{42}$ Corroborating these findings, this study demonstrated that protein levels of iNOS and COX-2 were increased by $\mathrm{H}_{2} \mathrm{O}_{2}$ induced SIPS in HDFs but malvidin treatment inhibited expression of both enzymes in a dose-dependent manner. Inhibition of iNOS and COX-2 protein expression by malvidin may be related to regulation of NF- $\mathrm{\kappa B}$ signaling.

The tumor suppresser protein $\mathrm{p} 53$ is activated by DNA damage induced by oxidative stress and triggers expression of p21, which influences cell aging. ${ }^{13}$ Moreover, p53 and p21 activation can lead to intracellular ROS production during establishment of senescence. ${ }^{43}$ Activation of p53 leads to overexpression of cyclin-dependent kinase inhibitors, including p21, and may influence HIF-1, which is related to adaptation to oxidative stress. Indeed, activated p53 induced by oxidative stress can lead to apoptosis or growth arrest at the G1 phase. ${ }^{28}$ In our study, expres- 
sion levels of p53 and p21 were elevated under SIPS induced by $\mathrm{H}_{2} \mathrm{O}_{2}$. However, malvidin treatment produced dose-dependent downregulation of $\mathrm{p} 53$ and $\mathrm{p} 21$ protein expression. These results suggest that malvidin produces anti-aging effects through regulation of the cell cycle and apoptotic processes. Numerous proteins are involved in the process of apoptosis, including pro-apoptotic regulator Bax and anti-apoptotic regulator Bcl-2. ${ }^{44}$ Bax regulates the activities of tumor suppressor factors such as p53, caspases, and endonucleases by extricating cytochrome $c$ from mitochondria, while Bcl-2 prevents the release of cytochrome $c^{45}$ Corresponding to previous studies, our present study showed that HDFs under SIPS strongly upregulated Bax expression and downregulated Bcl-2 expression. However, malvidin treatment regulated protein expression both Bax and Bcl-2, suggesting a protective effect against apoptosis.

The present study demonstrates that malvidin protects against premature cellular senescence induced by oxidative stress. Malvidin treatment following induction of SIPS elevated cell viability and inhibited lipid peroxidation. Malvidin treatment regulated the NF-KB signaling pathway and apoptosis-related factors. Furthermore, malvidin treatment extended the cellular lifespan. These results demonstrate that malvidin could inhibit the aging process by attenuating oxidative stress.

\section{ACKNOWLEDGMENTS}

This work was supported by a 2-Year Research Grant of Pusan National University.

\section{CONFLICTS OF INTEREST}

No potential conflicts of interest were disclosed.

\section{REFERENCES}

1. Colle D, Arantes LP, Rauber R, de Mattos SE, Rocha JB, Nogueira $\mathrm{CW}$, et al. Antioxidant properties of Taraxacum officinale fruit extract are involved in the protective effect against cellular death induced by sodium nitroprusside in brain of rats. Pharm Biol 2012;50:883-91.

2. Finkel T, Holbrook NJ. Oxidants, oxidative stress and the biology of ageing. Nature 2000;408:239-47.

3. Brieger K, Schiavone S, Miller FJ Jr, Krause KH. Reactive oxygen species: from health to disease. Swiss Med Wkly 2012;142: w13659.

4. Cencioni C, Spallotta F, Martelli F, Valente S, Mai A, Zeiher AM, et al. Oxidative stress and epigenetic regulation in ageing and age-related diseases. Int J Mol Sci 2013;14:17643-63.

5. Reichelt J, Schachtschabel DO. Energetic stress induces premature aging of diploid human fibroblasts (Wi-38) in vitro. Arch
Gerontol Geriatr 2001:32:219-31.

6. Bognar E, Sarszegi Z, Szabo A, Debreceni B, Kalman N, Tucsek Z, et al. Antioxidant and anti-inflammatory effects in RAW264.7 macrophages of malvidin, a major red wine polyphenol. PLoS One 2013;8:e65355.

7. Kabe Y, Ando K, Hirao S, Yoshida M, Handa H. Redox regulation of NF-kappaB activation: distinct redox regulation between the cytoplasm and the nucleus. Antioxid Redox Signal 2005;7:395-403.

8. Thanan R, Oikawa S, Hiraku Y, Ohnishi S, Ma N, Pinlaor S, et al. Oxidative stress and its significant roles in neurodegenerative diseases and cancer. Int J Mol Sci 2014;16:193-217.

9. Sinha-Hikim I, Sinha-Hikim AP, Shen R, Kim HJ, French SW, Vaziri ND, et al. A novel cystine based antioxidant attenuates oxidative stress and hepatic steatosis in diet-induced obese mice. Exp Mol Pathol 2011;91:419-28.

10. Salminen A, Hyttinen JM, Kaarniranta $K$. AMP-activated protein kinase inhibits NF- $\mathrm{KB}$ signaling and inflammation: impact on healthspan and lifespan. J Mol Med (Berl) 2011;89:667-76.

11. Lee CH, Han DS, Kim BM, Baek NM, Baik BK. Antioxidant and anti-hypertensive activity of anthocyanin-rich extracts from hulless pigmented barley cultivars. Int J Food Sci Technol 2013;48:984-91.

12. Huang WY, Wang J, Liu YM, Zheng QS, Li CY. Inhibitory effect of Malvidin on TNF- $\alpha$-induced inflammatory response in endothelial cells. Eur J Pharmacol 2014;723:67-72.

13. Toussaint $\mathrm{O}$, Medrano EE, von Zglinicki T. Cellular and molecular mechanisms of stress-induced premature senescence (SIPS) of human diploid fibroblasts and melanocytes. Exp Gerontol 2000;35:927-45.

14. Wolf FI, Torsello A, Covacci V, Fasanella S, Montanari M, Boninsegna $\mathrm{A}$, et al. Oxidative DNA damage as a marker of aging in WI-38 human fibroblasts. Exp Gerontol 2002;37:647-56.

15. Mosmann T. Rapid colorimetric assay for cellular growth and survival: application to proliferation and cytotoxicity assays. J Immunol Methods 1983;65:55-63.

16. Mihara M, Uchiyama M. Determination of malonaldehyde precursor in tissues by thiobarbituric acid test. Anal Biochem 1978; 86:271-8.

17. Rosner BA, Cristofalo VJ. Changes in specific dexamethasone binding during aging in WI-38 cells. Endocrinology 1981;108: 1965-71.

18. Cristofalo VJ, Charpentier R. A standard procedure for cultivating human diploid fibroblast like cells to study cellular aging. J Tissue Culture Methods 1980;3\&4:117-21.

19. Komatsu S, Yang G, Khan M, Onodera H, Toki S, Yamaguchi M. Over-expression of calcium-dependent protein kinase 13 and calreticulin interacting protein 1 confers cold tolerance on rice plants. Mol Genet Genom 2007:277:713-23.

20. Ashok BT, Ali R. The aging paradox: free radical theory of aging. Exp Gerontol 1999:34:293-303.

21. Tae KS, Kim SJ. Inhibition of iNOS and DNA oxidation by methanol extract of Schizonepeta tenuifolia. Trop J Pharm Res 2012;11:397-404.

22. Sastre J, Pallardó FV, Viña J. Mitochondrial oxidative stress plays a key role in aging and apoptosis. IUBMB Life 2000;49:427-35.

23. Satué-Gracia MT, Heinonen M, Frankel EN. Anthocyanins as antioxidants on human low-density lipoprotein and lecithin-liposome systems. J Agric Food Chem 1997;45:3362-7.

24. Kähkönen MP, Heinonen M. Antioxidant activity of anthocyanins and their aglycons. J Agric Food Chem 2003;51:628-33. 
25. de Gaulejac NSC, Glories Y, Vivas N. Free radical scavenging effect of anthocyanins in red wines. Food Res Int 1999:32:327-33.

26. Paixão J, Dinis TC, Almeida LM. Malvidin-3-glucoside protects endothelial cells up-regulating endothelial NO synthase and inhibiting peroxynitrite-induced NF-kB activation. Chem Biol Interact 2012;199:192-200

27. Hayflick L, Moorhead PS. The serial cultivation of human diploid cell strains. Exp Cell Res 1961;25:585-621.

28. de Magalhães JP, Chainiaux F, de Longueville F, Mainfroid V, Migeot V. Marcq L, et al. Gene expression and regulation in $\mathrm{H}_{2} \mathrm{O}_{2}$-induced premature senescence of human foreskin fibroblasts expressing or not telomerase. Exp Gerontol 2004;39:1379-89.

29. Kurz DJ, Decary S, Hong Y, Trivier E, Akhmedov A, Erusalimsky JD. Chronic oxidative stress compromises telomere integrity and accelerates the onset of senescence in human endothelial cells. J Cell Sci 2004:117:2417-26.

30. Matuoka K, Chen KY, Takenawa T. Rapid reversion of aging phenotypes by nicotinamide through possible modulation of histone acetylation. Cell Mol Life Sci 2001;58:2108-16.

31. Satoh A, Yokozawa T, Cho EJ, Okamoto T, Sei Y. Antioxidative effects related to the potential anti-aging properties of the Chinese prescription Kangen-karyu and Carthami Flos in senescence-accelerated mice. Arch Gerontol Geriatr 2004:39:69-82.

32. Liochev SI. Reactive oxygen species and the free radical theory of aging. Free Radic Biol Med 2013;60:1-4.

33. Morlière $P$, Santus R. Pro-oxidant role of superoxide dismutase in ultraviolet-A-induced lipid peroxidation in cultured normal human skin fibroblasts. Eur J Biochem 1998;256:184-9.

34. Niu Y, Na L, Feng R, Gong L, Zhao Y, Li Q, et al. The phytochemical, EGCG, extends lifespan by reducing liver and kidney function damage and improving age-associated inflammation and oxidative stress in healthy rats. Aging Cell 2013;12:1041-9.

35. Hayflick L. Current theories of biological aging. Fed Proc 1975;
34:9-13.

36. Yegorov YE, Zelenin AV. Duration of senescent cell survival in vitro as a characteristic of organism longevity, an additional to the proliferative potential of fibroblasts. FEBS Lett 2003;541:6-10.

37. Ginn-Pease ME, Whisler RL. Redox signals and NF-kappaB activation in T cells. Free Radic Biol Med 1998;25:346-61.

38. Choi YJ, Uehara Y, Park JY, Kim SJ, Kim SR, Lee HW, et al. MHY884, a newly synthesized tyrosinase inhibitor, suppresses UVB-induced activation of NF-KB signaling pathway through the downregulation of oxidative stress. Bioorg Med Chem Lett 2014:24:1344-8.

39. Choi MJ, Kim BK, Park KY, Yokozawa T, Song YO, Cho EJ. Anti-aging effects of cyanidin under a stress-induced premature senescence cellular system. Biol Pharm Bull 2010;33:421-6.

40. Chung HY, Kim HJ, Kim KW, Choi JS, Yu BP. Molecular inflammation hypothesis of aging based on the anti-aging mechanism of calorie restriction. Microsc Res Tech 2002;59:264-72.

41. Korbecki J, Baranowska-Bosiacka I, Gutowska I, Chlubek D. The effect of reactive oxygen species on the synthesis of prostanoids from arachidonic acid. J Physiol Pharmacol 2013;64:409-21.

42. Feng L, Xia Y, Garcia GE, Hwang D, Wilson CB. Involvement of reactive oxygen intermediates in cyclooxygenase-2 expression induced by interleukin-1, tumor necrosis factor-alpha, and lipopolysaccharide. J Clin Invest 1995:95:1669-75.

43. Borodkina A, Shatrova A, Abushik P, Nikolsky N, Burova E. Interaction between ROS dependent DNA damage, mitochondria and p38 MAPK underlies senescence of human adult stem cells. Aging (Albany NY) 2014;6:481-95.

44. Schuler M, Green DR. Mechanisms of p53-dependent apoptosis. Biochem Soc Trans 2001;29:684-8.

45. Green DR, Reed JC. Mitochondria and apoptosis. Science 1998; 281:1309-12. 